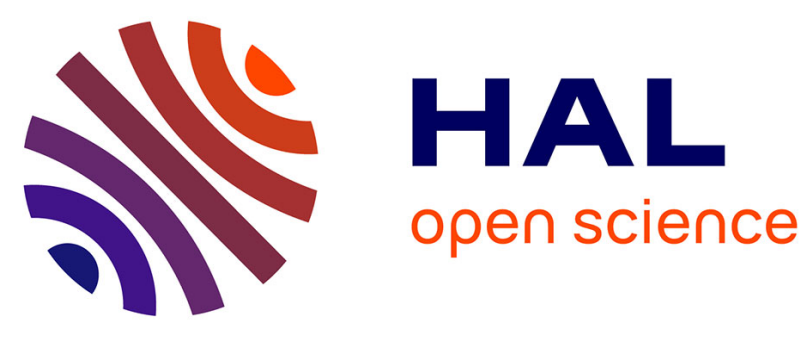

\title{
Parallel detection in liquid phase of N-channel MOSFET/ChemFET microdevices using saturation mode
}

Florian Larramendy, Fabrice Mathieu, Samuel Charlot, Liviu Nicu, Pierre Temple-Boyer

\section{To cite this version:}

Florian Larramendy, Fabrice Mathieu, Samuel Charlot, Liviu Nicu, Pierre Temple-Boyer. Parallel detection in liquid phase of N-channel MOSFET/ChemFET microdevices using saturation mode. Sensors and Actuators B: Chemical, 2013, 176, pp.379-385. 10.1016/j.snb.2012.09.091 . hal-01508106

\section{HAL Id: hal-01508106 https://hal.science/hal-01508106}

Submitted on 13 Apr 2017

HAL is a multi-disciplinary open access archive for the deposit and dissemination of scientific research documents, whether they are published or not. The documents may come from teaching and research institutions in France or abroad, or from public or private research centers.
L'archive ouverte pluridisciplinaire HAL, est destinée au dépôt et à la diffusion de documents scientifiques de niveau recherche, publiés ou non, émanant des établissements d'enseignement et de recherche français ou étrangers, des laboratoires publics ou privés. 


\title{
Parallel detection in liquid phase of $\mathrm{N}$-channel MOSFET/ChemFET microdevices using saturation mode
}

\author{
Florian Larramendy ${ }^{1,2}$, Fabrice Mathieu ${ }^{1,2}$, Samuel Charlot ${ }^{1,2}$, \\ Liviu Nicu ${ }^{1,2}$, Pierre Temple-Boyer $^{1,2}$ \\ ${ }^{1}$ CNRS, LAAS, 7 avenue du colonel Roche, F-31400 Toulouse, France \\ ${ }^{2}$ Université de Toulouse, UPS, LAAS, F-31400 Toulouse, France
}

\begin{abstract}
MOSFET and ChemFET are currently being used in many types of applications for the measurement of electrochemical potential and $\mathrm{pH}$ in liquid phase. This paper presents the realization of an analysis micro device including the micro sensor chip, the on-board electronic and the associated fluidics. The whole micro system can be easily transported, used for cellular cultures monitoring or chemical test thanks to a specific electronic interface. Using the transistor saturation mode, this interface enables both static and dynamic measurements for ChemFET and MOSFET-based devices, reducing electrical measurement interferences (up to $50 \mathrm{~dB}$ ) coming from the liquid phase.
\end{abstract}

Keywords: MOSFET, ChemFET, dynamic measurements, on board electronics 


\section{Introduction}

Research in the field of biosensors has enormously increased over the recent years, dealing with numerous detection/transduction principles. In the frame of electrochemistry, amperometry and potentiometry were especially developed. As a result, among the large range of biosensors, two kinds of integrated sensors rose: microelectrodes [1] and chemical field effect transistors (ChemFET) [2]. Each microsensors family has their own drawbacks and advantages and are finally complementary, offering a large panel of biological analysis [1-4]. Nevertheless, although the use of silicon-based technology deviated from microelectronics, both of them allow the development of micro/nanodevices networks to deal with multi-analysis strategies. This was demonstrated for CMOS-based microelectrode arrays [5] and successfully realized for the genome sequencing using ChemFET-based CMOS technology [6]. Furthermore, this multi-analysis approach is also fully compatible with the monitoring of cells cultures, leading to the realization of multi electrode arrays (MEA) and metal-oxide-semiconductor field effect transistor (MOSFET) based integrated circuits. Both technologies were used for the measurement of cellular electrochemical parameters [7-9] and of neuronal activities [10,11]. Nevertheless, compared to the MEA one, the FET technology was shown to be more adapted for such application. Indeed, the use of an inert upper oxide layer allows a direct measurement and contact with cells while preventing any interfering electrochemical reactions or any biological troubles [12]. Thus, Fromherz et al. have demonstrated that it can be possible to measure action potentials using MOSFET-based devices $[13,14]$ and others works related to neural cells $[15,16]$ or neural cultures [17] were successfully developed and presented in the literature. In this frame, one of the main interests is related to the monitoring of neurons network thanks to an integrated MOSFET and/or ChemFET array. However, when it comes to such complex bio-electronics interfaces, one of the measurement drawbacks is related to the complex microenvironment-related electrochemical noise and/or interferences that can hide the biological signal to be measured. As a result, it is important to control interferences voltages and currents coming from the water-based, conductive, analysis solution. In this article, a strategy to optimize the bioelectronics interface is addressed while using MOSFET and ChemFET microdevices for a parallel analysis of neurons cells in liquid phase. 


\section{Experimental procedure}

\section{A. MOSFET/ChemFET microdevices fabrication}

The field-effect transistors (FET) transistor micro devices fabrication is based on a standard ChemFET technology [18]. Yet, by introducing a specific metallization step in the fabrication process, both ChemFET and MOSFET microdevices were realized at once. Thus, the final chip includes 16 field-effect transistors suited to parallel detection. The starting substrate is a 6 inches, $\langle 100\rangle, \mathrm{N}$-type silicon wafer (resistivity of $400 \Omega . \mathrm{cm}$ ). The electrical insulation between each transistor was realized thanks to a standard P-well technology based on a Boron (B) implantation with a dose of $5 \times 10^{11} \mathrm{~cm}^{-2}$. Then, arsenic (As) implantation was performed with a dose of $10^{16} \mathrm{~cm}^{-2}$. In order to realize N-doped source and drain zones, a $50 \mathrm{~nm}$ thermal oxide $\left(\mathrm{SiO}_{2}\right)$ layer and a $50 \mathrm{~nm}$ silicon nitride $\left(\mathrm{Si}_{3} \mathrm{~N}_{4}\right)$ layer sequentially developed formed the $\mathrm{pH}$-sensitive gate area. Finally, after opening the source and drain contact zones, lift-off process was used to pattern a Titanium/Gold (Ti/Au) layer used for metallization contact and gate. Meanwhile, large area $\left(\sim 7850 \mu \mathrm{m}^{2}\right) \mathrm{Ti} / \mathrm{Au}$ microelectrodes were integrated to be used as non-ideal-reference electrode in order to ground the liquid media. After this step, pH-ChemFET $\left(\mathrm{SiO}_{2} / \mathrm{Si}_{3} \mathrm{~N}_{4}\right.$ gate) and MOSFET $\left(\mathrm{SiO}_{2} / \mathrm{Si}_{3} \mathrm{~N}_{4} / \mathrm{Ti} / \mathrm{Au}\right.$ gate) microdevices were completed (Fig. 1). At the end, two kind of chips were realized, one with 12 pH-ChemFET and 4 MOSFET (Fig. 2 a) and the other with 16 MOSFET (Fig. 2 b).

Finally, wafer-level packaging process was performed using the SU-8 technology. In our case, SU-8, a commonly used epoxy-based negative photo-resist was used to define the gate area, to passivate the chip surface, to isolate the electrical connections from the liquid environment and to fabricate fluidic micro devices while using the "stepper technology" in a non-standard way [19].

\section{B. Packaging process}

The line of sight of our FETs sensing platform is the activity monitoring of neurons culture. For this to be successfully achieved, analysis microdevices have to be realized in order to take into account specific physical and/or biochemical treatments: cleaning, sterilization, incubation processes. As a result, a special packaging process was developed in terms of silicon chip, printed circuit board (PCB), connectors and glass ring, inspired by Hierlemann works $[5,10]$. To meet the different requirements, chips are assembled on 
individual PCB supports. The chip packaging on PCB was realized using the "Flip-Chip" technique. This method allows a direct connection between the chip and its support by avoiding wire bonding. However, in such configuration an opening must be realized in the PCB in order to have a convenient access to the chip. As every chip has forty pads of connection, the screen printing technique coupled with the under bump metallurgy (UBM) one was the best method to collectively deposit as many bumps as needed on the PCB (Fig. 3 a). Finally, using adapted temperature and pressure parameters, the chips were fully mounted (Fig. 3 b).

In order to avoid contact with the liquid phase, metallic connections and bumps were protected using the "Under fill" technique. A biocompatible epoxy resin (E301 from Epotek) was used because of its low viscosity $(200 \mathrm{cps})$ and its thermal reticulation at room temperature. Eventually, to finish the packaging process and integrate a fluidic analysis tank on top of the chip, a Pyrex ring was stuck to the printed circuit board using another biocompatible epoxy resin (E353ND-T from Epotek) with a high viscosity (10000 cps). Thus, the whole micro system including the ChemFET/MOSFET chip, the waterproof tank and the printed circuit board designed to be easily plugged in an electronic interface, was finally realized (Fig. 4).

\section{Experimental set-up}

Before its realization, the electronic interface was designed and simulated using PSpice software. According to the simulations results and in agreement with the ChemFET/MOSFET implemented technology, the FET-based microdevices were biased using a drain-source current $I_{D S}$ and a drain-source voltage $V_{D S}$ respectively equal to $250 \mu \mathrm{A}$ and $2 \mathrm{~V}$. For the liquid phase analysis, three kinds of reference electrodes were tested to bias the liquid sample to the ground $\left(\mathrm{V}_{\mathrm{G}}=\mathrm{OV}\right)$ : the Ti/Au microelectrode integrated on the chip, a gold wire and a commercial silver / silver chloride $\mathrm{Ag} / \mathrm{AgCl}$ reference electrode (purchased from Metrohm). Furthermore, supplementary $\mathrm{Ti} / \mathrm{Au}$ integrated microelectrodes on the chip were used to measure in parallel and simultaneously the potentiometric noise $V_{\text {Noise }}$. Whatever the microdevices tested, i.e. ChemFET or MOSFET, all these measurement parameters were kept constant.

Since our ChemFET technology was previously characterized in previous work [18], a simple test was performed in order to check the electrochemical behavior. Thus, three different $\mathrm{pH}$ buffered solutions $(\mathrm{pH}=4.0,7.0,10.0$, purchased from Sigma) were studied 
while using the commercial $\mathrm{Ag} / \mathrm{AgCl}$ reference electrode. For the first buffer $(\mathrm{pH}=4.0)$, all natural offsets of each ChemFET transistor were deduced and removed automatically by the oscilloscope so as to have only static variations generated by the $\mathrm{pH}$ ones.

Concerning MOSFET devices, they were first tested in a classical way by currentvoltage experiment to check their electrical characteristics. Then, same devices were studied in liquid samples while mimicking neuronal signals. In order to do so, different artificial electrical action potential-like voltages (a $-70 \mathrm{mV}$ resting potential and extremum voltage of $100 \mathrm{mV}$ and $+30 \mathrm{mV}$ ) were generated by a signal generator (AFG3102 from Tektronix) and applied to different MOSFET gates to test their electrical behavior as well as the independence of their respective electrical measurement. Such experiments were performed in three different liquid media, i.e. deionized water, phosphate buffered solution ( $\mathrm{PBS}, \mathrm{pH}=7.4$, purchased from Sigma) and Dubelcco's Modified Eagle's medium (DMEM) culture field (purchased from Hyclone), using the three different electrodes to bias the liquid phase, i.e. the $\mathrm{Ti} / \mathrm{Au}$ integrated one, the gold wire and the $\mathrm{Ag} / \mathrm{AgCl}$ commercial one.

\section{Results and discussion}

\section{A. Electronic formalism}

In this work, the electronic scheme is based on the saturation mode. This configuration allows reducing the field noise due to adapted feedback control while ensuring the exclusive measurement of signals generated by biological phenomena. From the electrical point of view, the studied chip is associated to a FET network which vocation is to measure any electrochemical variation on the FET's metallic gates or pH-sensitive surfaces. It is assumed that all the field effect transistors have conventional behaviour and obey to the well-known equations between the drain-source current $I_{D S}$, the drain-source voltage $V_{D S}$ and the gatesource voltage $V_{G S}$. According to the imposed bias conditions, the FET-based devices are placed in the saturation mode $\left(V_{G S}>V_{\text {th }}\right.$ and $\left.V_{D S}>V_{G S}-V_{\text {th }}\right)$. As a result, the drain-source current is:

$$
I_{D S}=K\left(V_{G S}-V_{T}\right)^{2}\left(1+\frac{V_{D S}}{V_{A}}\right)
$$

where $V_{A}$ is the Early's voltage, $V_{T}$ is the FET threshold voltage and $K$ stands for the MOSFET transistor intrinsic coefficient. 
According to equation (1), the source voltage $V_{S}$ is representative of the gate voltage $V_{G}$ and any gate voltage variations will be duplicated by the source one, as given by (2).

$$
V_{S}=V_{G}-V_{T}-\sqrt{\frac{I_{D S}}{K} \frac{V_{A}}{V_{A}+V_{D S}}}
$$

Since the threshold voltage $V_{T}$ and the Early's voltage $V_{A}$ can be considered as constant whatever the electrical bias, the output voltage variations (i.e. the source potential $V_{S}$ variations) can be determined as follows:

$$
\frac{d V_{S}}{d V_{D S}}=\frac{1}{2} \sqrt{\frac{I_{D} V_{A}}{K}}\left(V_{A}+V_{D S}\right)^{-\frac{3}{2}}
$$

It appears that the drain-source current IDS must be low while the drain-source voltage $V_{D S}$ must be high to minimize errors generated by the $V_{D S}$ variations. Different measurements have shown that the worst FET transistor has an Early's voltage $V_{A}$ ranging between $35 \mathrm{~V}$ and $105 \mathrm{~V}$. As the MOSFET transistor intrinsic coefficient $K$ is a constant parameter (estimated around $\left.16 \times 10^{-5} \mathrm{~A} / \mathrm{V}^{2}\right)$ and according to our data and to the standard electrical bias used $\left(I_{D S}=\right.$ $250 \mu \mathrm{A}, V_{D S}=2 \mathrm{~V}$ ), these errors are shown to be lower than $1 \%$, demonstrating the efficiency of our measurement principle.

\section{B. Electronic scheme}

Since all MOSFET devices were collectively fabricated on the same chip, they have similar electrical behaviour (dispersion lower than 1\%). Typical current-voltage characteristics are presented in Fig. 5, evidencing a threshold voltage $\mathrm{V}_{\mathrm{T}}$ around $1.2 \mathrm{~V}$ and a $\mathrm{I}_{\mathrm{on}} / \mathrm{I}_{\mathrm{off}}$ ratio higher than 3000 . As a result, since current mirrors insure the current generation to insure that all drain-source current values $I_{D S}$ are similar (Fig. 6) and in the absence of any stimulation signal, all the transistor gates are at the same potential. Due to the chosen electronic scheme, all the transistors are biased in the same way while the $V_{D S}$ voltage value is fixed on one transistor only (Fig. 6). The source voltage being imposed by the gate, the drain voltage is automatically set at $V_{S}+V_{D S}$ voltage (from the feedback) and it is imposed to all the transistors. Finally, the source potentials of the different FET devices (from $V_{S 1}$ to $V_{S n}$ ) are used as output voltages (from $V_{\text {outo-1 }}$ to $V_{\text {out } 0-n}$ ), allowing to monitor multiple chemical variation signals $V_{\text {out } 0-I}$ (Fig.5). 
Since all the FET transistors gates are in contact with the liquid media, one has to be able to avoid the electrochemical noise/interference that might affect the accuracy of the final measurement results. For this to be achieved, a differential amplifier is implemented next to the $\left(V_{\text {out } 0-1}-V_{\text {out } 0-n}\right)$ level in order to subtract the gate voltage (and its electrochemical noise) from the different output voltages (Fig. 7).

Finally, the transfer equation (between $V_{\text {out } 0-i}$ and $V_{\text {out } 1-i}$ ) of this amplifier is given by equation (4).

$$
V_{o_{\text {Atnt }}}=(k+1)\left(V_{o \text { ont }}-V_{N o}\right)
$$

In our case, the $\mathrm{k}$ factor was chosen equal to 1 according to electronic devices, leading to a final amplification gain of 2. Finally, the last amplification stage allows removing the DC components (typical frequencies lower than $200 \mathrm{mHz}$ ) by means of a high-pass filter with a gain of 1 .

\section{Electronic simulation}

Before realizing the electronic device, simulation was performed using P-Spice. An "action potential-like" shape was chosen as modelof the input biological electrical signal to be measured by the FETs sensing platform. This signal has a resting potential around $-70 \mathrm{mV}$ and variation of $130 \mathrm{mV}$ from peak to peak (Fig. 8 a). The liquid phase noise $V_{\text {Noise }}$ was assumed to be a sinusoidal signal with a voltage of $1 \mathrm{~V}$ from peak to peak and a frequence of $800 \mathrm{~Hz}$ (not shown). This signal was deliberately chosen with a large amplitude to study the performances of our measurement system. Action potential signals are simulated on $V_{i n 1}, V_{i n 2}$ and $V_{i n 3}$ sequentially whereas $V_{\text {Noise }}$ is simulated on $V_{i n n}$. Output of $V_{\text {out2-1 }}$ is shown in Fig. 8 b), evidencing the correct measurement of the action potential signal sent on $V_{i n}$. The field noise voltage has been decreased as shown in Fig. 6 c) on the $V_{\text {out2-n }}$ signal. All other signals are returned with insignificant noise field and an amplification of 2.

From the $V_{\text {out } 2-n}$ signal, the amplitude is estimated at $2 \mathrm{mV}$ peak to peak. Whatever the signal frequency (and therefore the $800 \mathrm{~Hz}$ interfering noise), the gain of the common mode $\mathrm{G}_{\mathrm{CM}}$ is given by the equation (5). According to our experimental results, the $\mathrm{G}_{\mathrm{CM}}$ value was estimated around to $2 \times 10^{-3}$ (or a Common Mode Rejection Ratio (CMRR) around 54dB). 


$$
G_{C M}=\left(\frac{V_{o} \mathrm{Q}-1 t}{V_{N o}}\right)
$$

\section{Test in liquid media}

The $\mathrm{SiO}_{2} / \mathrm{Si}_{3} \mathrm{~N}_{4} \mathrm{pH}$-chemFETs were characterized using the gold wire or the $\mathrm{Ag} / \mathrm{AgCl}$ commercial reference electrode in order to bias a liquid solution which $\mathrm{pH}$ variation has to be assessed. In this conventional configuration, a $\mathrm{pH}$-sensitivity around $50 \mathrm{mV} / \mathrm{pH}$ was determined which is in good agreement with previous results [18,20] (Fig. 9). However, the use of the $\mathrm{Ti} / \mathrm{Au}$ integrated microelectrode was responsible for an important sensitivity decrease resulting in a $28 \mathrm{mV} / \mathrm{pH}$ final value. Such phenomenon might be due to electrochemical defects related to the gold surface and/or to the titanium underlayer. Nevertheless, such results were obtained whatever the pH-ChemFET transistors tested, demonstrating the reproducibility of our technological process.

The MOSFET devices were first tested in PBS solution by pairs (at least). Using the integrated $\mathrm{Ti} / \mathrm{Au}$ electrode, measurements of action potential-like voltages were polluted by other signals in the liquid phase as shown in figure $10 \mathrm{a}$ ) and b). The signal to noise ratio was estimated around 2.3. On the contrary, with the gold wire or with the $\mathrm{Ag} / \mathrm{AgCl}$ commercial reference (Fig $8 \mathrm{c}$ and $\mathrm{d}$ ) and as previously for the $\mathrm{pH}$ measurement, results are improved since no parasitic signals were evidenced. In fact, in this latter case, the signal to noise ratio was estimated at 15.5. These results were confirmed through the liquid noise measurement using a non-stimulated MOSFET transistor. For the integrated Ti/Au microelectrode (Fig. 11 a), all the different action potential-like signals were fully recorded while none of them were evidenced when the gold wire or the commercial $\mathrm{Ag} / \mathrm{AgCl}$ reference electrode was used (Fig. 11 b). Finally, since identical results were obtained in the DMEM culture field, the good use of these two last electrodes was demonstrated for the monitoring of neuronal cultures.

Finally, deionized water was also tested in such configuration. Again, the efficiency of the gold wire or of the $\mathrm{Ag} / \mathrm{AgCl}$ commercial electrode was confirmed. Nevertheless better results were obtained since the signal to noise ratio was around 2.9 for the Ti/Au integrated microelectrode and up to 25 for the other ones. Such improvements are due to the much higher resistivity of deionized water $(\sim 10 \mathrm{M} \Omega . \mathrm{cm})$ compared to the PBS solution $(\sim 50 \Omega . \mathrm{cm})$.

\section{Conclusion}


In this article, a FET-based (MOSFET/ChemFET) sensing platform dedicated to bioelectrical measurements in liquid media has been fabricated and successfully tested due to an innovative chip/support assembling technique combining screen printing and flip chip methods. A specific associated electronics scheme has been implemented to exploit the transistors saturation regime in order to both measure $\mathrm{pH}$ variation (static mode) and bioelectrical signals variation (dynamic mode). Electrical tests in liquid phase have shown a modification of signal on noise ratio between deionized water and phosphate buffer solution / DMEM culture field solution, as well as between gold microelectrode integrated on chip and gold wire commercial electrode. Hence, by studying different kinds of liquids and different electrodes to bias the liquid phase, the liquid noise voltage was reduced by more than $20 \mathrm{~dB}$. All MOSFET tests were realized providing action potential-like signals generation thus demonstrating that the system could be used to measure neuronal activities.

\section{References}

[1] D.W. Kimmel, G. Leblanc, M.E. Meschievitz, D.E. Cliffel, "Electrochemical sensors and biosensors", Analytical Chemistry vol. 84, pp.685-707, 2012.

[2] P. Bergveld, "Thirty years of ISFETOLOGY What happened in the past 30 years and what may happen in the next 30 years", Sensors and Actuators B, vol. 88, pp.1-20, 2003.

[3] M.J. Schöning and A. Poghossian, "Recent advances in biologically sensitive field-effect transistors (BioFET)", Analyst, vol. 127, pp. 1137-1151, 2002.

[4] R. Koncki, "Recent developments in potentiometric biosensors for biomedical analysis", Analytica Chimica Acta, vol. 599, pp. 7-15, 2007.

[5] U. Frey, J. Sedivy, F. Heer, R. Pedron, M. Ballini, J. Mueller, D. Bakkum, S. Hafizovic, F. D. Faraci, F. Greve, K.U. Kirstein and A. Hierlemann, "Switch-matrix-based high-density microelectrode array in CMOS technology", IEEE Journal of Solid-State Circuit, vol. 45, pp. 467-482, 2010.

[6] J.M. Rothberg, W. Hinz, T.M. Rearick, J. Schultz, W. Mileski, M. Davey, J.H. Leamon, K. Johnson, M.J. Milgrew, M. Edwards, J. Hoon, J.F. Simons, D. Marran, J.W. Myers, J.F. Davidson, A. Branting, J.R. Nobile, B.P. Puc, D. Light, T.A. Clark, M. Huber, J.T. Branciforte, I.B. Stoner, S.E. Cawley, M. Lyons, Y.T. Fu, N. Homer, M. Sedova, X. Miao, B. Reed, J. Sabina, E. Feierstein, M. Schorn, M. Alanjary, E. Dimalanta, D. Dressman, R. 
Kasinskas, T. Sokolsky, J.A. Fidanza, E. Namsaraev, K.J. McKernan, A. Williams, G.T. Roth, J. Bustillo, "An integrated semiconductor device enabling non-optical genome sequencing", Nature, vol. 475, pp.348-352, 2011.

[7] J.M. Cuadra, J.R. Alvarez-Sanchez, D. de Santos, V. Lorente, J.M. Ferrandez, F. de la Paz, E. Fernandez, "Response calibration in neuroblastoma cultures over multielectrode array", Neurocomputing, vol. 75, pp. 98-105, 2012.

[8] C. Xie, Z. Lin, L. Hanson, Y. Cui and B. Cui, "Intracellular recording of action potentials by nanopillar electroporation", Nature Nanotechnology, vol. 7, pp. 185-290, 2012.

[9] X. Duan, R. Gao, P. Xie, T. Cohen-Karni, Q. Qing, H. S. Choe, B. Tian, X. Jiang and C. M. Lieber, "Intracellular recordings of action potentials by an extracellular nanoscale fieldeffect transistor", Nature nanotechnology, Vol. 7, pp. 174-179, 2012.

[10] I.L. Jones, P. Livi, M.K. Lewandowska, M. Fiscella, B. Roscic and A. Hierlemann, "The potential of microelectrode arrays and microelectronics for biomedical research and diagnostics", Analytical and Bioanalytical Chemistry, pp. 2313-2329, 2011.

[11] J.M. Fernandez, E. Fernandez, "Neural computation with cellular cultures", Natural Computing, vol. 11, pp. 175-183, 2012.

[12] P. Fromherz, "Neuroelectronic interfacing: semiconductor chips with ion channels, nerve cells and brain", Nanoelectronics and Information Technology, pp. 781-810, 2003

[13] R.A. Kaul, N. I. Syed and P. Fromherz, "Neuron-semiconductor chip with chemical synapse between identified neurons", Physical Reviews Letters, vol. 92, n 3, 2004.

[14] A. Lambacher, M. Jenkner, M. Merz, B. Eversmann, R.A. Kaul, F. Hofmann, R. Thewes and P. Fromherz, "Electrical imaging of neuronal activity by multi-transistor-array (MTA) recording at $7.8 \mu \mathrm{m}$ resolution", Applied Physics. A, vol. 79, pp. 1607-1611, 2004.

[15] G. Massobrio, A. Massobrio, L. Massobrio, P. Massobrio, "Silicon-based biosensor functionalised with carbon nanotubes to investigate neuronal electrical activity in $\mathrm{pH}$ stimulated environment: a modelling approach", Micro \& Nano Letters, vol. 6, pp.689-693, 2011.

[16] P.M. Bulai, P.G. Molchanov, A.A. Denisov, T.N. Pitlik, S.N. Cherenkevich "Extracellular electrical signals in a neuron-surface junction: model of heterogeneous membrane conductivity", European Biophysical Journal, pp. 319-327, 2012.

[17] S.P. Lin, M.C. Liu, T.Y. Chi and Y.S. Kang, "Characterization of functional biointerface on silicon nanowire MOSFET", IEEE EMBS, pp. 4766-4769, 2011. 
[18] P. Temple-Boyer, J. Launay, I. Humenyuk, T. Do Conto, A. Martinez, C. Bériet, A. Grisel, "Study of front-side connected chemical field effect transistor for water analysis", Microelectronics Reliability, 44, p.443-447, 2004.

[19] F. Larramendy, L. Mazenq, P. Temple-Boyer and L. Nicu, "Three-dimensional closed microfluidic channel fabrication by stepper projection single step lithography: the diabolo effect", Lab on Chip, vol.12, pp. 387-390, 2012.

[20] W. Sant, P. Temple-Boyer, E. Chanié, J. Launay and A. Martinez: "On-line monitoring of urea using enzymatic field effect transistors", Sensors and Actuators B, vol. 160, pp. 5964 (2011).

\section{Biographies}

Florian Larramendy was born in Brive-la-Gaillarde, France, in 1986. He received the M.S. degree in microelectronic system engineering from the Paul Sabatier University, Toulouse, France, in 2009. He joined the Laboratory for Analysis and Architecture of Systems (LAAS), National Center of Scientific Research (CNRS), Toulouse in 2009 as PhD student. He is in charge of the development of microsystems to measure neuronal activities.

Fabrice Mathieu was born in Orléans, France, in 1972. He received the engineering degree in communication systems and electronics from the CNAM (Conservatoire National des Arts et Métiers), Toulouse, France, in 2003. He joined the Laboratoire d'Analyse et d'Architecture des Systèmes (LAAS), Centre National de la Recherche Scientifique (CNRS), Toulouse, in 2001, where he is currently in charge of the development and design of very low signal detection systems applied to the micro(nano)electromechanical systems area and its complete electronic treatment and control for automation.

Samuel Charlot was born in 1979, he received the master degree in Materials and Micro Technology from the Var Institute of Technology, Toulon, France in 2004. From 2004 to 2006, he worked on the development of microfluidics systems in LAAS-CNRS, Toulouse, France. In 2006, he worked in the packaging of oxygen sensor at Néosens, Labège, France. From 2007 to 2008, he worked on a low cost technology for the integration of sensors silicon in polymer microfluidic systems in LAAS-CNRS, Toulouse, France. Since 2008, he works on 
packaging area and more specifically in screen printing technology and flip chip interconnect technology in the team packaging in LAAS-CNRS, Toulouse, France.

Liviu Nicu was born in 1973 in Bucharest (Romania). After completing his master of electrical engineering at the Paul Sabatier University of Toulouse (France) in 1997, he joined the Integrated Microsystems Group at the LAAS (Laboratory for Analysis and Architecture of Systems) of Toulouse where he obtained his PhD. in 2000 into the Micromechanical Structures field. From 2000 to 2003, he was R\&D Engineer at Thales Avionics, Valence (France). His activities focused onto the development of micromechanical sensors for the civil and military navigation applications. Since 2003 he joined the NanoBioSystems Group at LAAS as a full time CNRS (National Center of Scientific Research) researcher where he currently works in two main research fields: the development of (1) new resonant bio(chemical)sensors using M(N)EMS technologies and of (2) cantilever-based microsystems for contact deposition of small amounts of biological samples for biochip applications.

Pierre Temple-Boyer was born in Montpellier (France) in 1966. He received his engineering master's degree in electronic from the Ecole Supérieure d'Electricité (Paris - France) in 1990 and his master's degree in microelectronics from the Université Paul Sabatier de Toulouse (France) in 1992. He joined the Laboratoire d'Architecture et d'Analyse des Systèmes of the French Centre National de la Recherche Scientifique (LAAS-CNRS) in 1992 and received the $\mathrm{PhD}$ degree from the Institut National des Sciences Appliquées de Toulouse (France) in 1995. Since then, as a senior researcher, he has been working on the development of micro- and nanotechnologies. 


\section{Figures caption}

Fig.1: Schematic of the $\mathrm{SiO}_{2} / \mathrm{Si}_{3} \mathrm{~N}_{4} / \mathrm{Ti} / \mathrm{Au}$ MOSFET device

Fig. 2: a) Photograph of the MOSFET/ChemFET chip and b) SU8-passivated MOSFET chip

Fig. 3: a) Photograph of bump deposit on PCB by screen printing technique and b) chip mounted on specific PCB

Fig. 4: Photograph of final packaging

Fig. 5: MOSFET electrical charateristics: Drain - Source Current IDS as a function of Drain Source and Gate - Source Voltages $V_{D S}$ and $V_{G S}$

Fig 6: Schematic view of the polarization system

Fig. 7: Schematic view of the amplification system

Fig. 8: a) Action potential implemented on $V_{\text {inl }}$, b) amplification system output $V_{\text {out2-1 }}$ and c) noise in $V_{\text {out2-n }}$ output

Fig. 9: pH-ChemFET analytical response (tested on 70 microdevices)

Fig. 10 : MOSFET measurements of action potential-like signals in PBS or DMEM with the $\mathrm{Ti} / \mathrm{Au}$ microelectrode integrated on chip

a) on transistor $1, \mathrm{~b}$ ) on transistor 2 and c) on the others transistors TX

Fig. 11: MOSFET measurements of action potential-like signals in PBS or DMEM with the commercial electrode or the gold wire

a) on transistor $1, \mathrm{~b}$ ) on transistor 2 and c) on the others transistors TX 


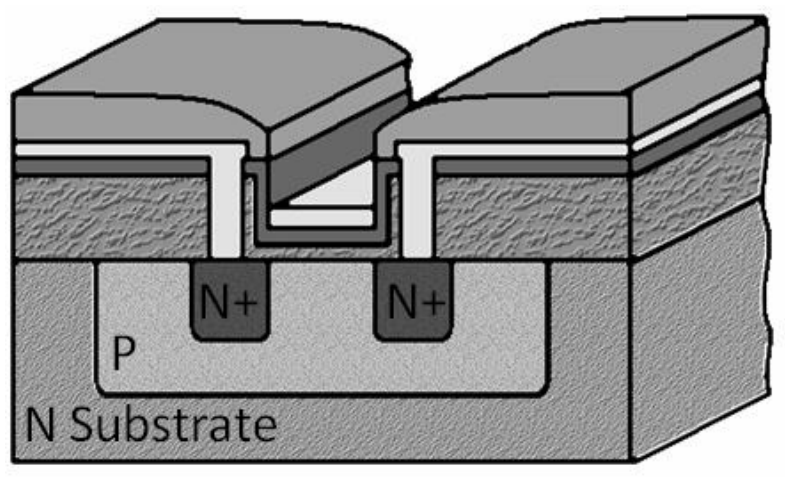

$\square$ SU-8 passivation

$\square \mathrm{Ti} /$ Au metallization

$\square \mathrm{Si}_{3} \mathrm{~N}_{4}$ ion-sensitive film

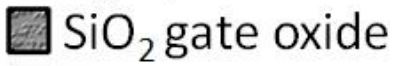

$\square \mathrm{N}+$ doped silicon drain/source

$\square \mathrm{P}$ doped silicon well

$\square \mathrm{N}$ type silicon substrate

Fig.1: Schematic of the $\mathrm{SiO}_{2} / \mathrm{Si}_{3} \mathrm{~N}_{4} / \mathrm{Ti} / \mathrm{Au}$ MOSFET device 


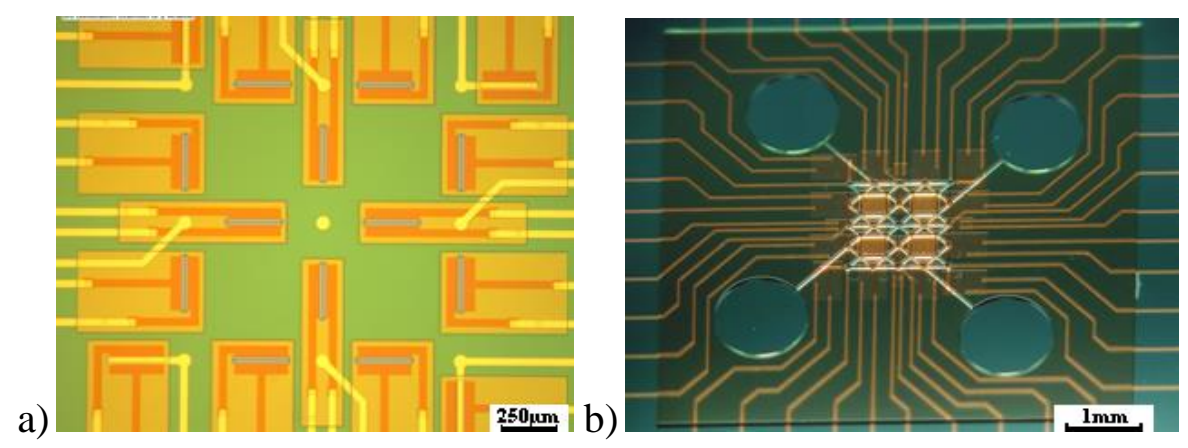

Fig. 2: a) Photograph of the MOSFET/ChemFET chip and b) SU8-passivated MOSFET chip 

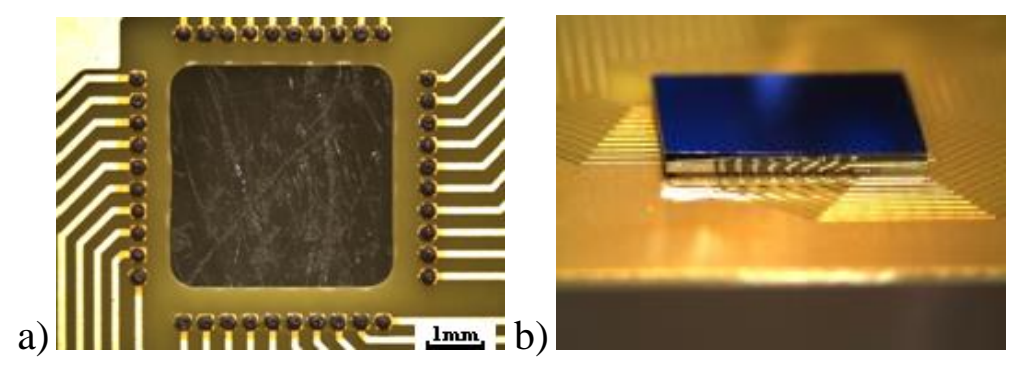

Fig. 3: a) Photograph of bump deposit on PCB by screen printing technique and b) chip mounted on specific PCB 


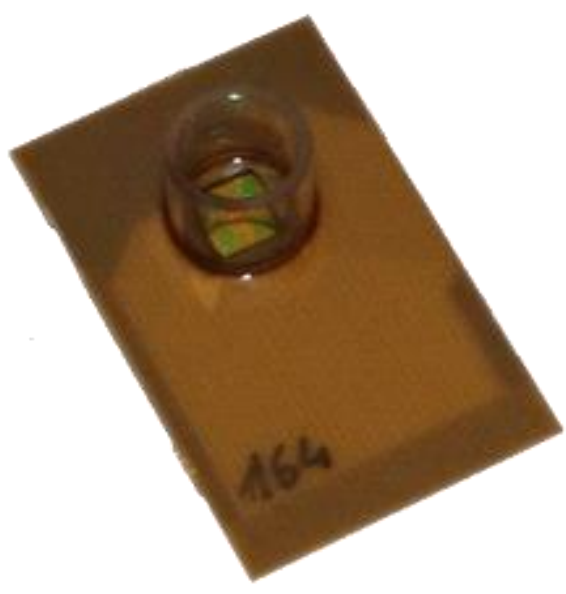

Fig. 4: Photograph of final packaging 


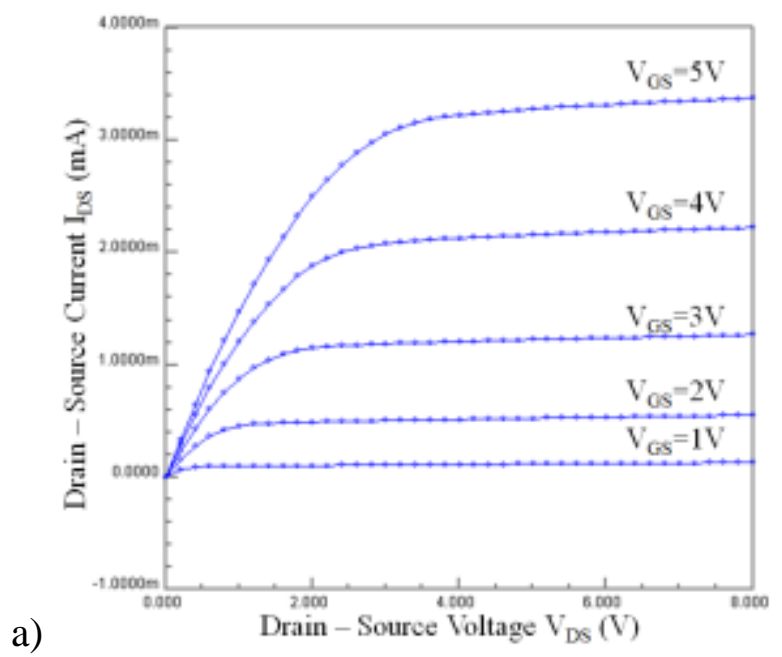

b)

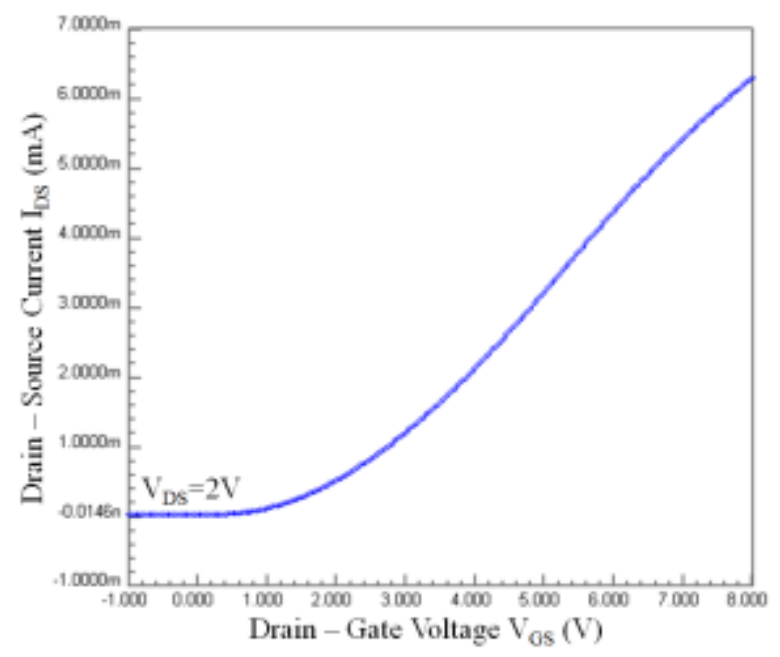

Fig. 5: MOSFET electrical characteristics: Drain - Source Current IDS as a function of Drain Source and Gate - Source Voltages $V_{D S}$ and $V_{G S}$ respectively 


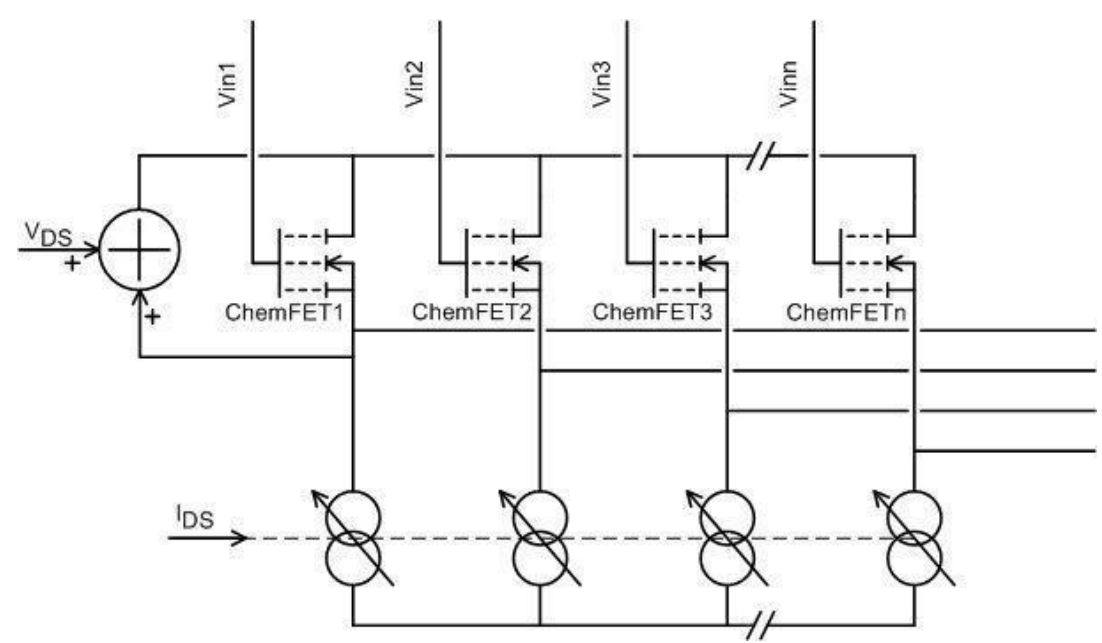

Fig 6: Schematic view of the polarization system 


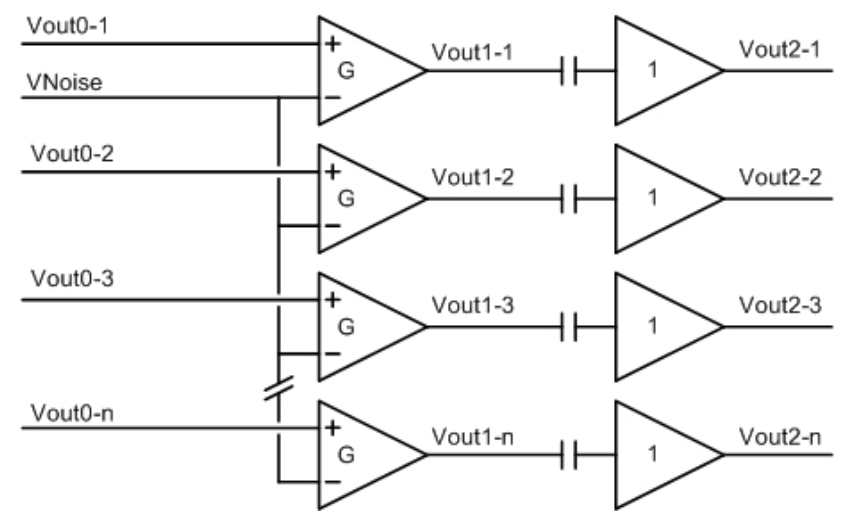

Fig. 7: Schematic view of the amplification system 


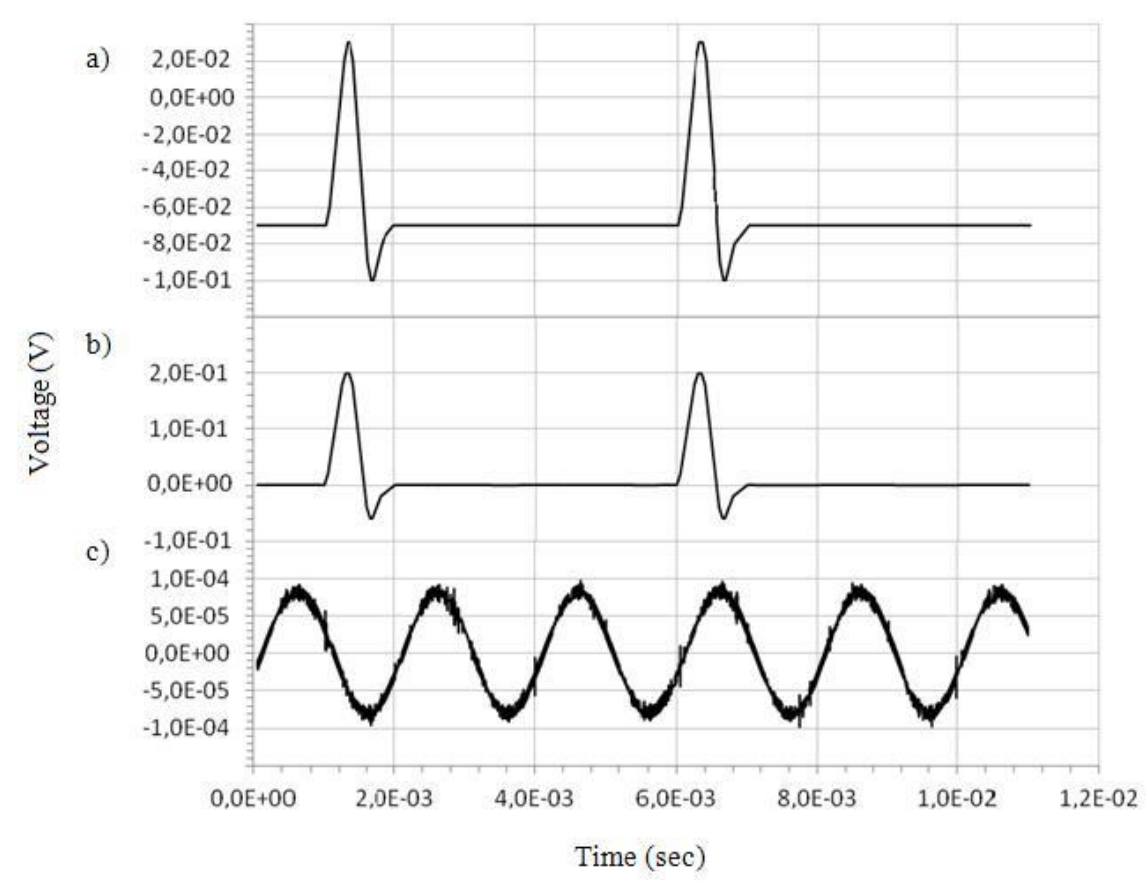

Fig. 8: a) Action potential implemented on $V_{\text {in } 1}$ b) amplification system output $V_{\text {out2-1 }}$ and c) noise in $V_{\text {out2-n }}$ output 


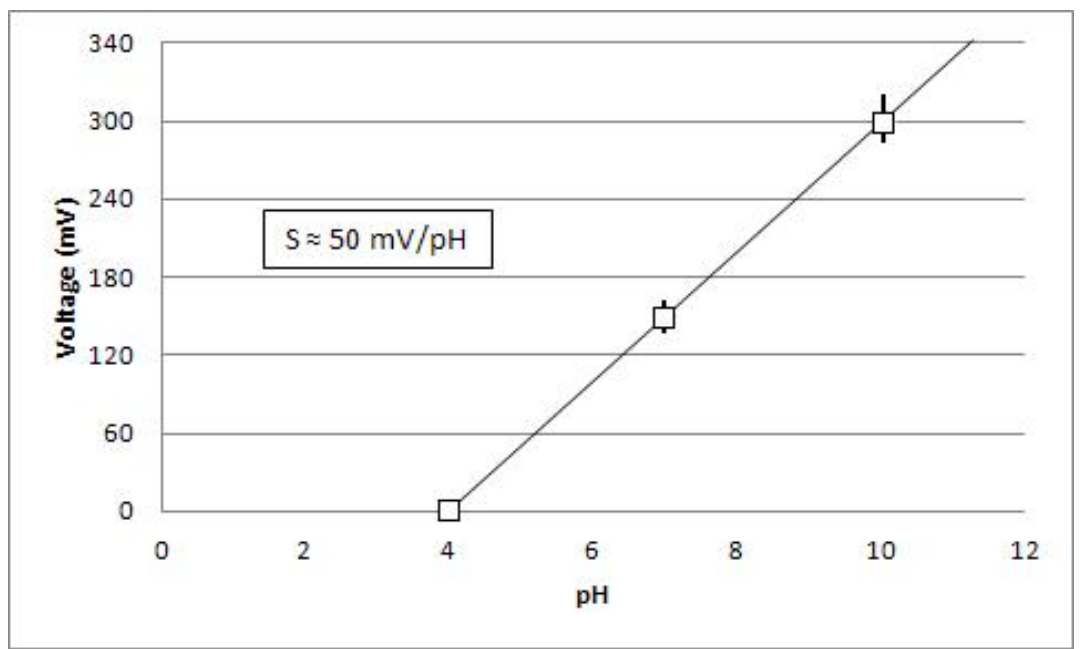

Fig. 9: $\mathrm{pH}-\mathrm{ChemFET}$ analytical response (tested on 70 microdevices) 

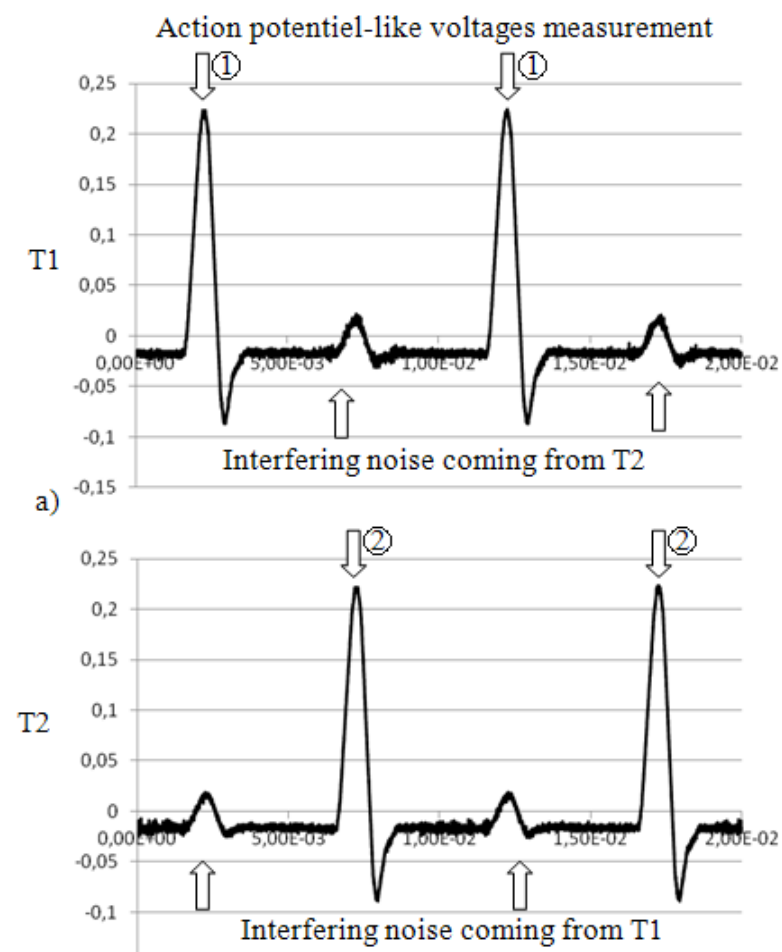

b) $-0,15$

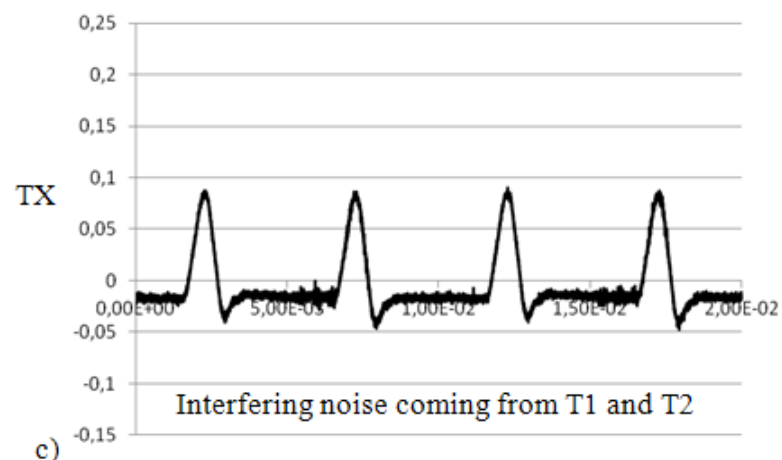

Fig. 10 : MOSFET measurements of action potential-like signals in PBS or DMEM with the $\mathrm{Ti} / \mathrm{Au}$ microelectrode integrated on chip a) on transistor 1, b) on transistor 2 and c) on the others transistors TX 


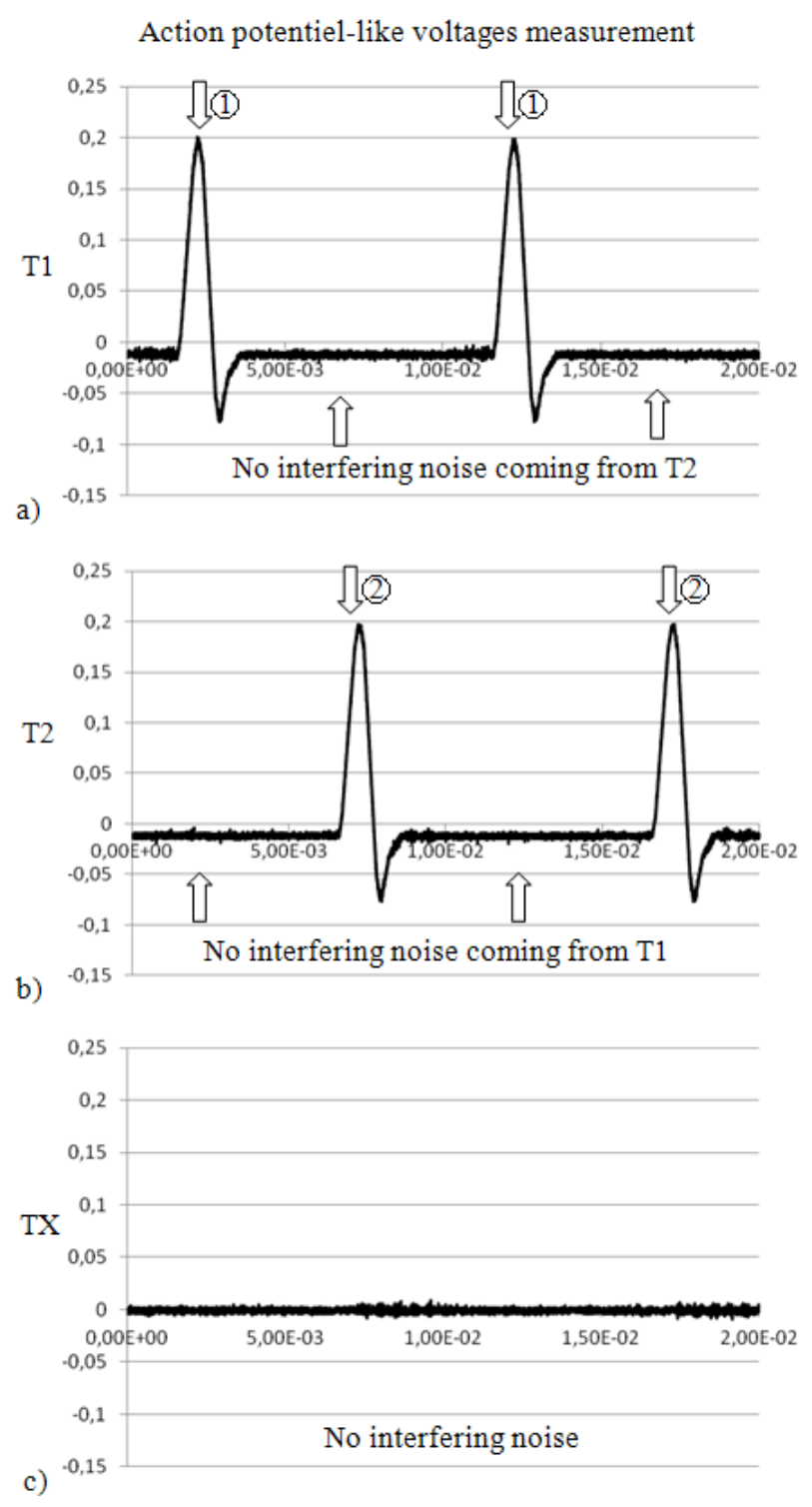

Fig. 11: MOSFET measurements of action potential-like signals in PBS or DMEM with the commercial electrode or the gold wire a) on transistor $\mathrm{T} 1, \mathrm{~b}$ ) on transistor $\mathrm{T} 2$ and c) on the others transistors $\mathrm{TX}$ 